\title{
Psychology and neurobiology of horror movies
}

Lauri Nummenmaa, PhD, Professor

Turku PET Centre, Department of Psychology and Turku University Hospital, University of Turku, Finland

This work was supported by Samsung Electronics Nordic AB

Contact information

Dr Lauri Nummenmaa,

Turku PET Centre,

Kiinamyllynkatu 4-6, 20520 Turku, Finland.

Email: lauri.nummenmaa@utu.fi

tel +358505747933

www: http://emotion.utu.fi 


\section{Summary}

This review covers the neurobiological and psychological aspects of fear and anxiety from the perspective of creating effective horror movies. The review begins with biological mechanisms of the fear response, and then discusses the specific techniques and strategies that may be used for generating powerful simulated fear experiences in movies. Movie audiences are not actually exposed to real threats, thus the events depicted in the movie should pass the brain's "reality check" systems and top-down emotion regulation strategies to engage the automatic fear responses in the brain. Because are social species, one powerful mechanism for this is the vicarious experience - automatic resonance of the movie character's somatic and motor states in the viewer. Most powerful general determinants of fear are the proximity of the threats, as well as their unpredictability. These can be significantly amplified with proper timing by carefully intermixing episodes of increasing and deceasing suspense with sudden intensely shocking events.

Some fears are nearly universal and thus powerful themes for horror movies. Fears of injury and illness as well as those pertaining to termination of social relationships are the most common ones in the general population. Similar fears are also sources of common clinical phobias, suggesting that that humans are genetically predisposed to fear specific life-threatening conditions and events. Survey data also show that scariest horror movies deal with this kind of universal themes. Because the fear system can potentiate learning, new fears can also be installed in the audience during the course of a movie. When coupled with the biologically universal determinants of fear, these novel, movie-specific fears can be made very potent. Soundscape is critical for horror, as auditory information is automatically and unconsciously processed even while focussing on the visuals. Specific acoustic features such as roughness constantly perceived as threatening and they also automatically activate the brain's fear circuit. These features can also be implemented in musical soundtracks to increase their scariness.

Horror movies are widely appealing, but more popular among males than females and for individuals with high personality factors of sensation seeking and aggression. Further, emotion recognition abilities increase and emotionality stabilizes towards the old age, making older audiences more difficult to scare. The paradoxical appeal of horror movies stems from three factors - universal human curiosity even towards morbid and threatening subjects, mixing of emotions of fear and excitement in the brain, as well as the capability to learn about own emotionality and dangerous situations safely in the context of movies. 


\section{Section 1: Psychological and neurobiological basis of fear Fear: Ancestral survival intelligence}

Fear is a protective mechanism that acts as "survival intelligence" in the brain, mind, and body. It has a strong and distinct evolutionary function as a response to acute threats to physical and psychological well-being. Fear is often equated with the subjective experience or feeling of dread. However, fear is a complex phenomenon that prepares the individual to meet the survival challenges by automatically adjusting cardiovascular, skeletomuscular and endocrine functions alongside actual behaviour and psychological processes including attention and memory ${ }^{1,2}$. This complex cascade of changes has one goal: to recruit physical and psychological resources for avoiding the danger in the first place by freezing and remaining hidden when the predator is still far away, or initiating fight-or-flight response when the threat is already imminent ${ }^{3}$. Fear is a biological universal, and practically everyone will respond with a broadly similar fashion in a life-threatening situation. This response is fast: the neural cascade leading to the fear response takes less than half a second to be completed in the brain. Because fear response optimizes survival changes, it can almost completely take over the control of both humans' and other animals' immediate actions no matter how pleasant or important their current activity would be. This happens because fear and other negative emotions signal potential injuries, discomfort or even death, thus they must be able to override positive emotions to ensure survival ${ }^{4}$. Accordingly, humans and other animals avoid in getting to fearful situations unless they might lead to significant gains - for example, prey might enter territory routinely patrolled by predators, if it knows that it can scavenge resources such as food or nesting material in the area.

Fear is a powerful emotion, because it alters what we hear and see. Fear potentiates attention and we automatically orient ourselves towards potential threats while our perceptual awareness and learning/memory mechanisms are enhanced ${ }^{5}$. Fear is also strongly corporal emotion, altering the state of numerous physiological systems. These lead to strongly felt subjective experiences in the body, making fear, panic and related states some of the most powerful experiences humans may have ${ }^{6,7}$. Fear feels unpleasant because it tries to motivate us for survival - the psychological experience signals presence of severe danger. Conversely, when the threat is gone the feeling of dread disappears, and this relief feels rewarding because it signals safety. Although our brains and minds almost instinctively know how to filter the fearful and dangerous information from the environment and respond to it, this knowledge cannot be necessarily readily conceptualized. Consequently, if we want to tailor the scariest possible events and scenes for the purposes of entertainment, we need to rely on controlled experiments and careful measurements of neural, physiological and psychological components of the fear response to distil the core determinants of human fears. 


\section{Brain basis of fear}

The fear response consists of a complex neurobiological and physiological cascade that ultimately leads to change in behaviour and psychological state of the individual (Figure 1). The brain's fear circuit operates at multiple time scales and it constantly evaluates distance and severity of different threats. The midbrain circuits operate at the immediate fight-or-flight situations where direct contact with the threat can no longer be avoided. The higher-level systems in the frontal cortex are involved in prevention and planning of avoidance when the threat is not yet imminent 8,9 . This dynamic interplay between higher-level volitional planning of escape strategies and automated fight-or-flight provides effective means for optimizing survival strategies at multiple time scales ${ }^{10}$. This explains why approaching a fearful situation feels so unnerving - when we for example get closer and closer to the snake that we dread but must nevertheless get our from our lawn, the midbrain defense circuits try to push us away while our higher-level executive system tries to fight back with them and get us to remove the snake from the lawn. Many horror video games exploit this dissonance to create almost unbearable levels of suspense. To destroy the supernatural threats that lurk around the dark corners in this type of games, the player actually has to muster up their courage and get terrifyingly close to the villains. Such constant push-pull activity between the approach and avoidance circuits in the brain can generate truly unnerving experiences.

Studies have constantly shown that a subcortical structure called amygdala is important for recognizing dangerous and behaviorally relevant information. Neuroimaging studies in healthy humans show that amygdala is consistently activated during fearful situations (see statistical summary in Figure 1A). In line with this, neurological patients with amygdala damage are unable to recognize fearful facial expressions or sounds 11,12. Amygdala is also critical for the experience of fear, as patients whose amygdala has been damaged are unable to feel that they are afraid in dangerous situations, such as when handling snakes or spiders ${ }^{13}$.

Frontal cortical systems support amygdala in generating the conscious experience of fear ("I am afraid") ${ }^{14}$ and coordinating complex, strategic escape and avoidance responses when the threats are still far away 8,9. Furthermore, these systems also support regulation of emotional responses by inhibiting amygdala activation ${ }^{15}$. This control is however far from perfect. When the threat becomes imminent, an automatic fight or flight response is triggered by midbrain structures ${ }^{16}$, and frontocortical emotion regulation breaks down. The ultimate goal of the fear response is to prepare the body for action - either freezing, flight or fight depending on the proximity of fear. These changes induce prominent corporal sensations $6,7,17$ that are mediated by the insula and somatosensory cortices (Figure 1A-B). Finally, fear and anxiety also increase attentional preparedness and vigilance promoting detection of threats (Figure 1C), 
and acute threats in the environment capture and hold attention effectively to ensure efficient detection and processing of survival-salient information 5,18.

\section{A) Brain responses to fear}

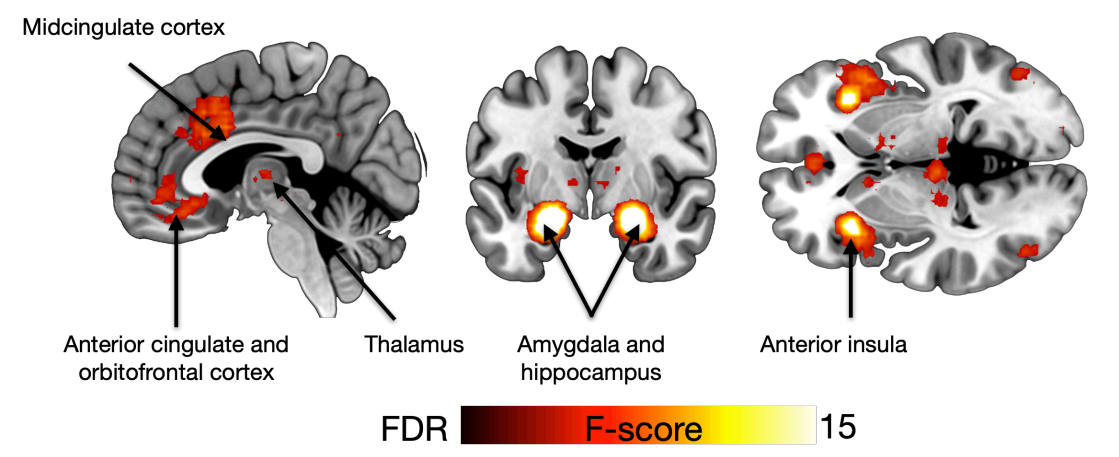

B) Bodily responses to fear

C) Attention shifts during fear

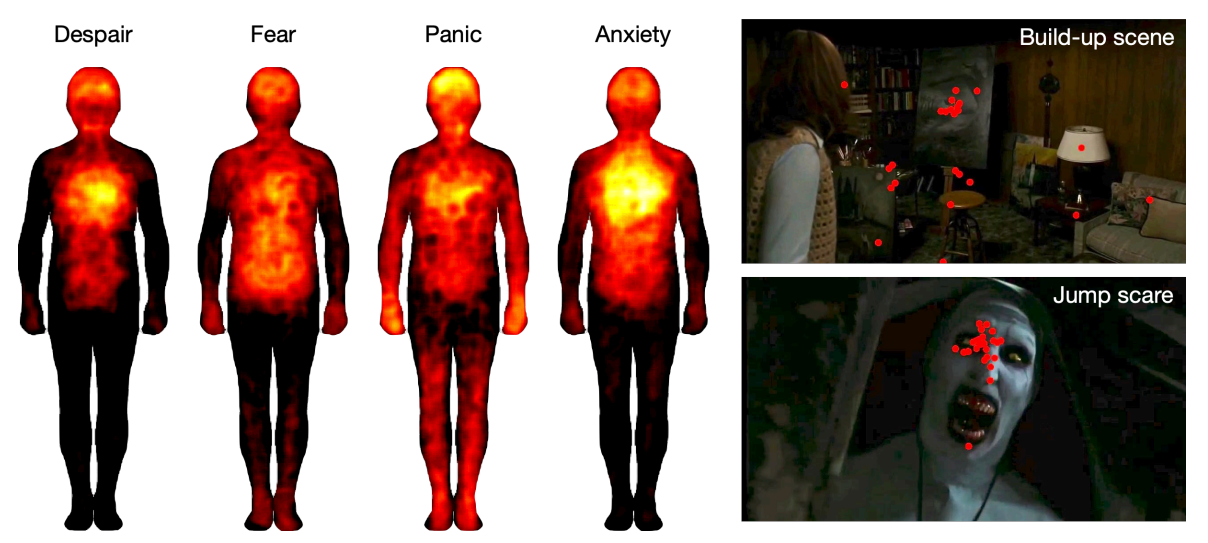

Figure 1. (A) Brain basis of fear. The figure summarizes brain regions responding consistently to fear across 363 functional magnetic resonance imaging studies. The analysis is based on the NeuroSynth database ${ }^{19}$ per August $4^{\text {th }} 2020$. (B) Bodily experiences during fear and related states. The colouring shows the relative intensity of nett bodily sensations during each feeling state, modified from ${ }^{7}$. (C) Illustration of narrowing of attentional focus during fear while watching a horror movie; each dot represents gaze position of a single individual. During neutral or less fearful situations viewers' eye movements are widely distributed, while intense shocks capture everyone's attention to the location of the threat.

\section{How horror movies affect the human brain}

The fear response is on many occasions automatic and uncontrollable. A visitor to a zoo might be shocked by a snake jumping against the glass of its cage, or an individual may tremble in the heights of a tower crane before making a bungee jump. In both examples the individuals feel fear despite knowing that they are actually safe. The snake is housed safely in the cage, and the bungee rope will eventually prevent the jumper from hitting the ground. Because automatic fear response precedes and often overrides the processing of contextual safety information, we may thus be startled even when we know that we are not threatened at all. Direct recordings from the 
amygdala show that this structure responds to fearful information, such as movies showing fearful facial expressions, in less than 120 milliseconds ${ }^{20}$. This is much faster than the prefrontal cortex can evaluate the contextual information. The "enjoyable fear" we experience during horror movies thus results from the interaction of the survival circuits that automatically respond to the threat cues such as sudden noises or predators, and the executive systems and long-term memory that evaluate the contextual information and confirm us constantly that we are safe. We would never go to see movies if we knew the killers would actually come after us or would never try a bungee jump if we knew the bungee rope would fail.

Amygdala activation recorded while viewing a horror movie is proportional to the subjectively felt fear ${ }^{21}$. Functional, whole-brain imaging studies (Figure 2) have shown that while viewing movies, brain activity of the viewers becomes time-locked not just in the sensory cortices that process the incoming information in same timescale, but also in the key nodes of the emotion and fear circuits ${ }^{22}$. Such synchronization is most prominent during the most aversive episodes, suggesting that fear and other negative emotions tune brains into intrinsic fight-or-flight survival mode that is consistent across viewers. In other words, horror movies thus make the viewers at least temporarily more similar to each other.
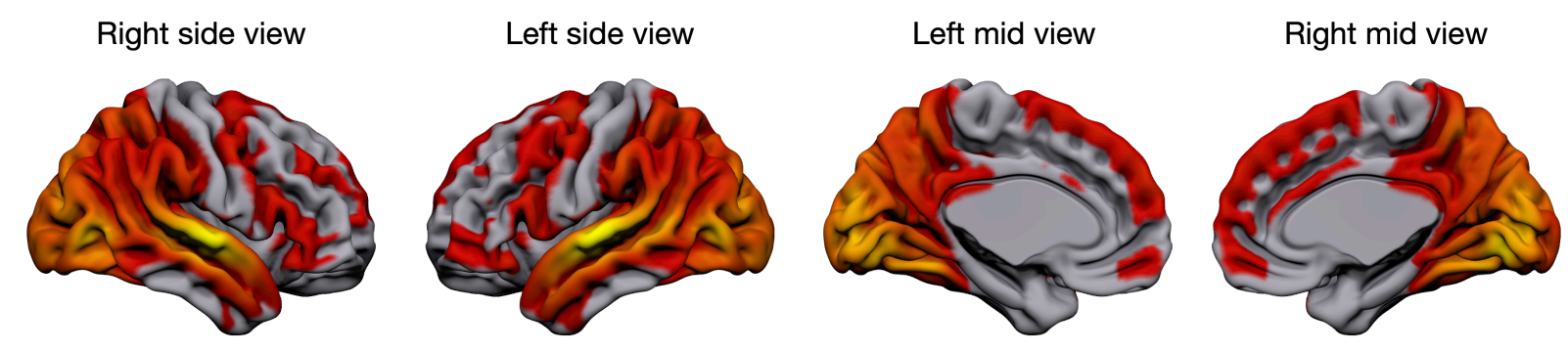

Low

High

Similarity of brain activity across viewers

Figure 2. While viewing a horror movie (Conjuring 2), brain activity becomes synchronized across viewers. This synchronization is particularly strong during the "jump-scare" episodes of the movies. Adapted from ${ }^{23}$.

Recommendations: Fear is a primordial response to threat that occurs automatically and is only partially suppressed by contextual knowledge and volition. Effective induction of fear thus needs to capitalize on engagement of the automatic component and minimization of the inhibitory effects of the emotion regulation and contextual processing systems. This can be achieved by minimizing the safety signals and immersing the viewers in the movie, for example with first-person camera runs and by ensuring undivided attention to the movie events, easily achievable with large screens and high-quality audio and visuals. 


\section{Section 2: Principles of translating fear science to movies Simulated fears}

Pleasures of the cinema are not only restricted to feeling positive emotions - many people find also horror movies enjoyable, despite their goal is to shock and scare the audience. Research shows that particularly male viewers, individuals lower in empathy, and those higher in sensation seeking and aggressiveness report more enjoyment of fright and violence ${ }^{24}$. Moreover, emotional experiences become progressively weaker after early adulthood ${ }^{17}$, and it is well known that emotion regulation ability increases during ageing ${ }^{25}$. Consequently, particularly younger audiences are easier to scare with movies, which is also reflected in the restrictions prohibiting showing of potentially traumatic or overly graphic movies to younger audiences.

Fear system has evolved to protect humans and other animals in situations where we may actually get hurt. It is thus perplexing why we may feel intense fear during artificial situations where we cannot definitely get hurt, such as reading a thriller watching a horror movie. The reason for this that humans are predisposed to thinking that whatever we see or hear is real. For majority of human history this was practically always true - there were very few instances when our sensations and perceptions did not reflect the external reality. This explains why arts such as theatre and movies are so effective - by default, we take our surroundings as real. Artists can thus fool the brain by making copies of the reality that are good enough to pass through to the brain's reality checking systems. Corresponding "simulations" principles apply to nearly all human perception: We make copies of the real physical environment, and enjoy these copies such as paintings, photographs or video games when the real experience cannot be achieved. Additionally, our imagination allows us to generate improved copies of the reality (such as enhanced photographs) or even completely unrealistic copies (such as science fiction movies) that allow the audiences to experience something that would be impossible in the real world. This greatly expands the experience horizon we have, as long as the simulated reality will pass as the real thing ${ }^{26}$.

Because the human mind is capable of conscious, internal thought, we have to constantly distinguish the external world from the internal world and perform numerous reality checks to assess whether our experiences and perceptions stem from the external environment. Extreme break-down of this may lead to hallucinations, that is, experiencing internal thoughts as stemming from the environment ${ }^{27}$. However, bypassing this reality filter can be exploited by books, photographs, movies, and other media. Place illusion refers to the experience that audience is actually situated in the virtual experience, whereas plausibility illusion refers to the experience that the events are actually happening. Research has shown that particularly the plausibility illusion is a major determinant of fears evoked by digital media such as games ${ }^{28}$. When fully 
engaged, these illusions give the audience the experience of "being there" or actually living and experiencing the events seen in the movie or described in a book.

While most powerful place and plausibility illusions can be generated by virtual reality, several factors can strengthen them significantly in other display formats such as in conventional movies. For example, large body of research shows that the more lifelike the reproductions of reality are, the stronger the brain responds to them ${ }^{29}$. Detailed visuals and audio are thus critical for immersing the audience in a movie. Low-grade image and sound effectively break the illusion that what is currently happening is real. Similarly big screens in theatres and in home theatres help the audience to immerse in the world of the movie: when the movie literally fills the whole field of view, external environment (such as living-room furniture) do not interfere with the illusion of being in the virtual world of the movie. The 3D surround sound in turn as the name suggests - surrounds the audience in the soundscape, giving a strong feeling of being in the middle of the action.

\section{Inducing fear with vicarious experience}

Fear has evolved to protect first-hand survival ${ }^{1,13}$, thus most potent fears emerge when our own well-being is at stake. In digital media, such first-hand experiences can readily be simulated with first-perspective 3D games and particularly in virtual reality, where players are literally experiencing the events happening to themselves. However, most conventional movies portrays events that are occurring to the movie characters, while spectators merely watch the events unfolding. But why do we experience the dangers occurring to the actors as scary? Because humans are an inherently social species, we have the tendency to automatically share emotions with each other - even with the characters in a movie. Our bodies thus freeze, and our heart begins to race, when we see Danny Tolloran driving around the corridors of the Overlook hotel in The Shining, ultimately bumping into the ghastly twins.

Observation of others in a particular emotional state such may trigger a behavioural and physiological "copy" of emotional state in the observer ${ }^{30-32}$. Neuroimaging studies have also revealed common neural activation for perception and experience of states such as pain ${ }^{33-35}$, disgust ${ }^{36}$, and pleasure ${ }^{37}$. Such vicarious experience of others' emotional states in one's own body and brain has supports social interaction via contextual understanding: Sharing others' emotional states provides the observers a bodily reference that helps in understanding their intentions and actions and allows to tune in or 'sync' with other individuals ${ }^{38-40}$. Such emotion transfer is often automatic: we know how difficult it is to resist yawning when seeing someone else yawn, or that it may be impossible not to burst into a laughter when hearing everyone else around us cracking up ${ }^{41,42}$. 
This kind of vicarious simulation or emotional contagion is a powerful means for emotion transfer, because we literally feel to be experiencing the same thing as someone else. Such emotional contagion is also engaged while viewing movies ${ }^{43}$. Via means of vicarious simulation, we can literally feel the tarantula on our hand when it's crawling over Indiana Jones on the screen or experience the terror of Wendy Torrance escaping her husband through the Overlook hotel in The Shining. To elicit powerful emotions via movies, it is thus imperative to engage the vicarious experience in the audience. Although vicarious simulation is often automatic ${ }^{34,44}$, there are well-known factors that bolster the contagion of others' emotions. We are much prone to engage in the emotions of people that are close to us, such as our friends, family and relatives 45,46. Conversely, we are less likely to mirror others' emotions when they are considered not to belong to our own group ${ }^{47}$. Others' behaviour influences whether we mirror their feelings - one study found that the perceived fairness of another person determines the degree of empathy towards them, with significantly greater emotional empathy toward fair individuals - most likely because we intuitively consider fair people to be on our side ${ }^{48}$. For the same reason, we automatically tend to side with the protagonist in the movie and feel their fortunes and misfortunes, whereas do not experience similar attachment towards the antagonist.

Recommendations: To evoke powerful vicarious fear, the movie must engage strong empathy towards the protagonist, and the viewers must be emotionally attached to them, experiencing to be on the same side with the protagonist. Consequently, the protagonist (exposed to threats) has to be likeable and feel familiar so that the audience will empathize with them. Vicarious experience is based on multiple factors, such as facial and vocal expressions, behaviour and also contextual factors - although others' emotional states can be cognitively inferred, direct mapping of others' expressions is more powerful. However, due to contextual influence it is more effective if the protagonist is seen as vulnerable (e.g. young, inexperienced) and thus more defenceless against the threats.

\section{Section 3: General determinants of fear Uncertainty and unknowns: The terrible twos}

Anxiety is a state that promotes active vigilance and prepares the mind and body for survival in uncertain situations but unlike fear, it does not have a clear target ${ }^{49}$. Uncertainty is stressing and it fuels our fears and anxiety ${ }^{50}$. One of the major functions of the brain and learning is to reduce uncertainties about the environment and allow the individual to better predict what will happen next. When these predictions are difficult to make, we experience the situation as unnerving. Fear of the unknown might actually be the most fundamental fears in humans ${ }^{51}$, and it explains a multitude of other fears: We are afraid of darkness because we never know what is hiding there, we are wary of strangers because we do not know how they will behave, and we find abandoned places creepy because we do not know why they have been deserted. 
This is why learning about the uncertainties feel so good - it signals that we are getting the situation under control. Brain imaging studies have accordingly found that learning to anticipate fearful situations that have not yet occurred engages the brain regions associated with pleasure and reward processing. However, this does not happen for unpredictable threats ${ }^{52}$. This means that when fear is used for entertainment, it has to be somewhat predictable to be enjoyable: We do not enjoy going into our home in the night finding a masked, bloody man creeping around with a knife, because we never wanted that to happen an did not expect to see that in the first place. However, seeing the same, horrifying scene in a movie can translate into an exciting experience, because we deliberately went to see the movie, we knew would contain such episodes.

Fear of uncertainty is also closely related to fear of loneliness: Social contacts are so critical to humans that lack of social support is actually one of the most important determinants of premature death ${ }^{53,54}$. When we are alone, we know that we are more exposed to our surroundings, making our life significantly less predictable. We automatically evaluate how competent the people surrounding us are in protecting us, and these evaluations reduce our anxiety towards threats when we consider to be in safe company ${ }^{55}$. Breaking this safety net by isolation and loneliness is thus a very powerful way of increasing anxiety and threat. The feeling of loneliness is easy to manipulate as it can stem from multiple factors, ranging from direct physical distance to others to perceived isolation and availability of support in, for example, a remote and desolate location.

\section{Fear of strangers}

Humans experience familiarity as safe, and both adults and children tend to seek companion from people that they experience similar to themselves ${ }^{56-58}$. We are naturally wary of strangers and people who seem different to us - most likely because we do not yet know what to expect from them. Consequently, we often have a tendency to consider in-group members as good and out-group members as bad or evil ${ }^{59}$, which unfortunately leads to numerous conflicts. For the same reason we are afraid of other creatures and creations that somehow resemble humans but are still different from us, such as zombies or corpses. It no coincidence that most horror movie villains and antagonists are humans or human-like creatures, and their common feature is that they are somehow different than the rest of us - either psychologically (e.g. Norman Bates in Psycho) or physically (e.g. Samara Morgan in The Ring or Freddy Krueger in A Nightmare on Elm Street). These characters play with our primordial fear of strangers and abnormalities. Such aversion for deviations from the prototypical human form does not follow a linear pattern (Figure 3). For example, humanoid-like robots are experienced relatively neutral because they are not considered as humans at all. Cartoon characters or plush toys are more human-like, and they are often more pleasant to us. However, when the human-likeness gets close - but not close enough. 
to a real human, there is a clear drop in the pleasantness of the objects: creatures and creations that are almost but not enough human-like elicit aversion, and they said to fall into the uncanny valley ${ }^{60}$. This applies to, for example, most current "realistic" androids and imperfect early 2000's 3D characters, but also to deformed humans or corpses that are definitely humans but still somehow different from what we expect humans typically to be.

This phenomenon of uncanny valley is consistently observed in both humans and nonhuman primates, suggesting that it is automatic and genetically determined rather than learned ${ }^{61,62}$. Landing the villains and antagonists in the middle of the uncanny valley is thus a powerful way for creating memorable and frightening characters, but it requires great deal of care. If the characters are unnatural enough (such as animated villains in Disney cartoons), they do not engage any aversion because they are too definitely non-human. Conversely too human-like characters may end up being likeable and elicit empathy.

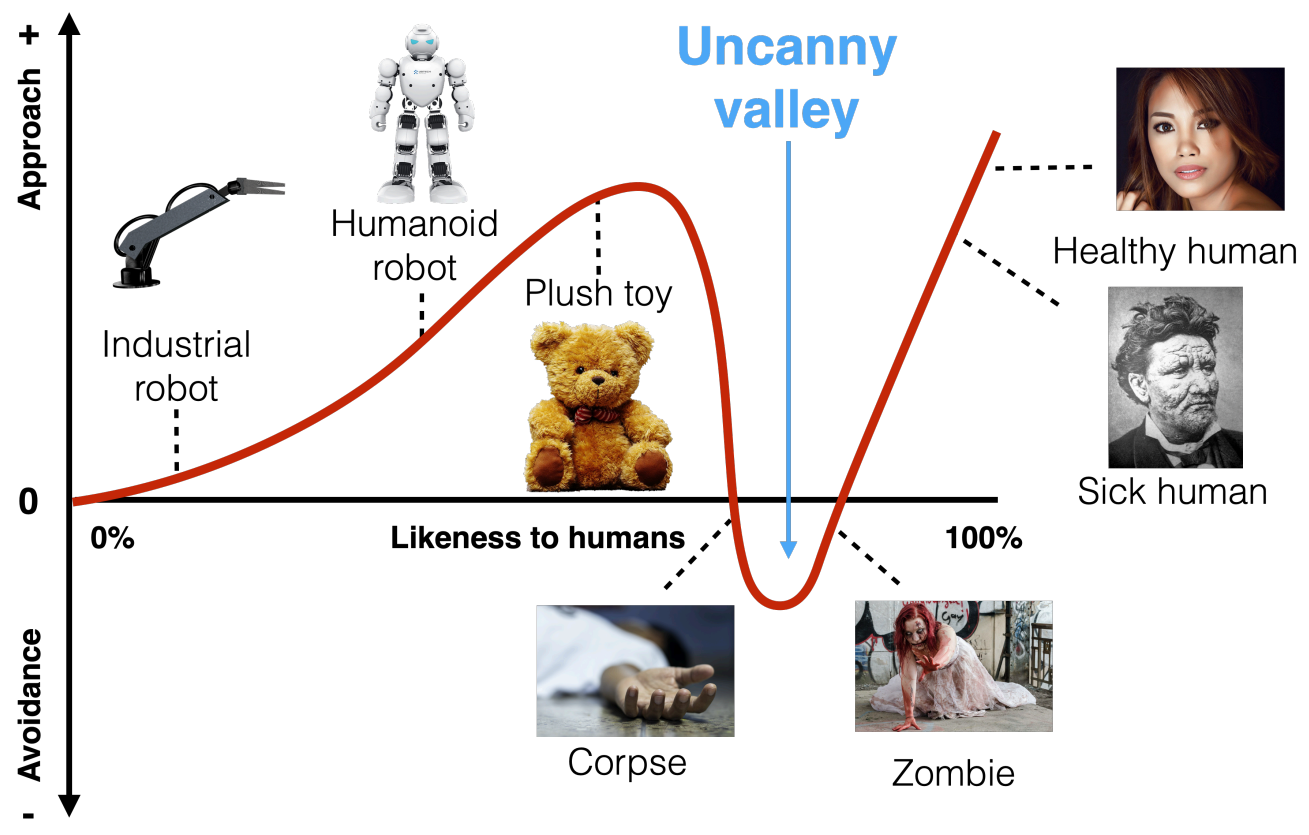

Figure 3. Illustration of the uncanny valley.

Recommendations: Imperfect copies of humans or human-like characters are dreadful because they fall into the uncanny valley. Great care must be taken to land the characters into the middle of the valley, so that they are not too grossly inhuman or too human-like. The similarity does not have to be physical, but it can also constitute of more subtle psychological factors such as personality, unnerving abnormalities in behavior, interests and so forth. 


\section{Fear of the dark}

Although darkness of a peaceful summer night in the countryside might be experienced as soothing, humans become increasingly alert when their surroundings are occluded. For example, simply blindfolding humans makes them feel anxious when they need to traverse novel environment ${ }^{63}$. Darkness also potentiates startle response - the most rudimentary reaction to surprising and potentially dangerous events ${ }^{64}$. Darkness is a powerful elicitor of fear and anxiety also due to the fact that brains are hard-wired to expect sensory stimulation and will do their best to work out a coherent representation even from imperfect input by filling in the missing details based on experience and memory. This explains why we are inclined to perceive crooked trees in dark forest as monsters, or mistake a piece of an old garment in the attic to a supernatural being ${ }^{65}$. These misperceptions are based on our experiences and memory, and the brain uses different top-down mechanisms for filling in the gap. Thus, we perceive the tree as a monster only if we have strong enough belief for existence of such beings, and a pre-existing memory template for filling in the details of the monster. This filling-in phenomenon is so ubiquitous that it also occurs in near absence of sensory inputs. For example, all over the world children play the conjuring game where, with appropriate rituals, they stare at a mirror in a dimly lit room and expect ghost or apparition (such as Bloody Mary or Hanako-San) to show up. Unlike many folk legends, this trick actually works but it does not involve any supernatural beings. When deprived of high-quality visual input while staring at the darkened mirror, the visual system starts guesswork to fill in the missing details, and the person staring at the mirror may perceive dead relatives or demons in the place of their own poorly lit face. In one experiment on this topic, almost $70 \%$ of subjects staring at a mirror in a dimly lit room saw their own face deforming, and almost half saw something that resembled a supernatural being ${ }^{66}$. These experiments show that darkness is a potent fear factor in movies, as it literally makes our imagination run wild, and if appropriate contextual information is provided (for example, the horror movie strongly hints that a killer or monster will appear from the darkness), the audience will automatically conjure threats and dreads to their mind's eye.

\section{Getting the timing right}

The fear system operates at multiple timescales. Distance from the threat is a major determinant for the intensity of fear and the corresponding protective response. When the potential threats are far away, humans rely on thinking, reasoning and other cognitive strategies for planning escape. However when the threat becomes so close that it seems unavoidable, there is a sudden shift towards automatic fight-or-flight circuitry in the midbrain structures 10,16. This means that in movies fear can be manipulated in two major ways: by inducing a slow phasic suspense that leads to anxiety-like state, as well as sudden, immediate shocks such as canonical "jump scares" when the fears may realize almost literally in the front of the viewers' eyes. 
The startle response is the most rudimentary reaction to external threats. It is a largely unconscious defensive reaction to threats such as sharp noises, rapid movements or other sudden changes in the environment. This brainstem refractory reflex consists of quick descending muscular contractions that begin from the head and that extend through the trunk and the knees ${ }^{67,68}$. Being startled feels unpleasant, and simple loud noises or flashes are enough to make most peoples' heart race, especially when they are already anxious due to, for example, looming noises coming out from the darkness. Startle responses are much stronger when in negative rather than in positive context. Accordingly, tuning the brain to expect forthcoming threats makes the actual protective responses stronger, because the emotion system "knows" that something bad will happen ${ }^{68}$. This startle phenomenon is famously implemented in the fast cuts in the shower scene in Alfred Hitchcock's Psycho, where the swift cuts in the edit lead to repeated startle responses potentiating the overall scariness of the scene.

Forewarnings of an upcoming danger may trigger emotional arousal, and the concomitant build-up of suspense would amplify the upcoming emotion-inducing scene. Indeed, studies have found that this kind of forewarning signals such as exposures to the frightening environment or hints about the dangerous nature of a locale significantly amplify the experiences of dread during the actual scary episode 69. Proper build-up of the forthcoming shocks in movies is thus imperative for maximizing the scariness. This is highlighted in Figure 4 that shows continuous fear ratings from a test audience viewing two feature horror films. Although the specific timing of the fearful episodes varies between the movies, there is also a consistent pattern seen in both films. To achieve powerful shocks, the intense scenes of dread are slowly built up and intermixed with calm and less intense episodes. Such variable suspense is necessary for achieving powerful shocks. For example, viewing an isolated 5-s jump scare event from a movie is not particularly scary, as it lacks the build-up and the viewer knows exactly that they will be scared during the next five seconds. For the same reason, viewing a medley consisting only of the jump scares in horror movies feels lame after a while, because the predictability is too high, and the build-up period is missing. This is because the brain quickly accommodates or adapts to repeatedly occurring events ${ }^{70}$, thus many pleasant and unpleasant experiences lose their power if repeated constantly expect some of those directly leading to vital failures, such as air hunger.

The elements of surprise and immediate shocks must thus be delivered cautiously - if every build-up of suspense leads to a major shocking scene, the predictability becomes too high, diluting the scariness. Positive, serene and humorous scenes can also be considered important for an effective horror movie: They generate the muchneeded breaks from the tensions, and the pleasure and laughter evoked by these scenes may act as a "safety signal" and the concomitant neurohormonal stress relief 
response will temporarily reset the fear and anxiety ${ }^{71}$, preparing the viewer to meet the next threat.
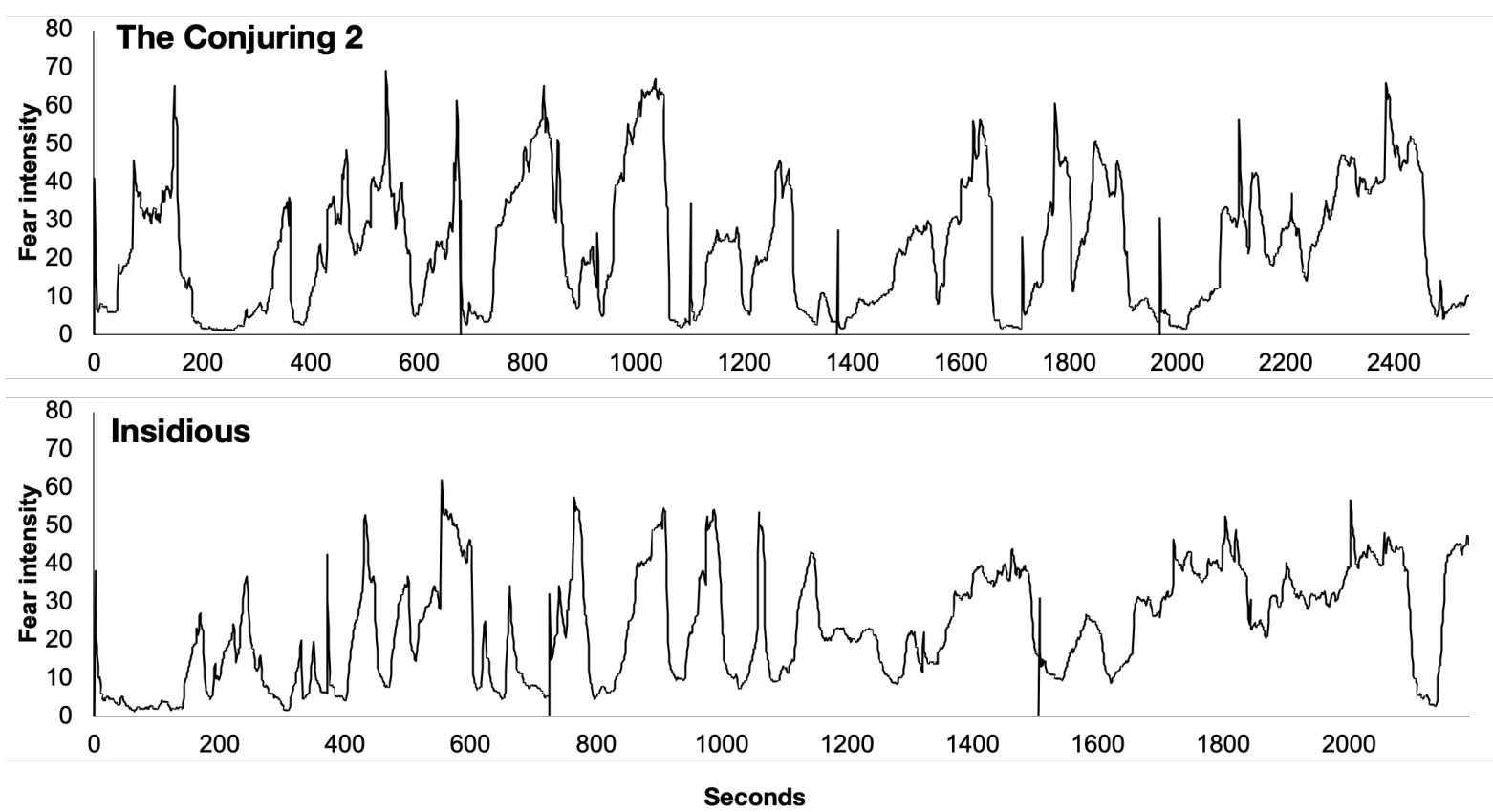

Figure 4. Mean time course of fear ratings from the experimental audience viewing two horror films (The Conjuring 2 and Insidious). Modified from ${ }^{23}$.

Generating the overall sense of suspense is also important, because it makes viewers more suspectable to supernatural beliefs, which are a common theme in horror movies. Belief in supernatural beings is strongest in the early childhood, where the distinction between real and imaginary has not yet sharpened ${ }^{72}$, yet many adults hold paranormal and supernatural beliefs. For example, in late adolescence / early adulthood, almost one third beliefs in horoscopes and ghosts, about half believe in paranormal phenomena such as UFOs and telepathy, and almost $80 \%$ believe in premonitory signs. Psychological studies show that under stressing and demanding situations people become increasingly superstitious and begin to believe in impossible or supernatural things ${ }^{73,74}$. Overall suspense and stressing events in movies makes this kind of phenomena more readily believable for adults in general too, increasing the audience's immersion to the virtual word of the movie.

Recommendations: In fear, timing is everything. Looming uncertainty and suspense do not just increase the excitement, but they also increase viewers' supernatural beliefs. Additionally, looming anxiety increases fear and survival responses during subsequent sudden shocks and scares. Additional unpredictability can be induced by occasionally shifting the movie's tone toward neutral or even positive, or by occasionally ramping up the anxiety without eventually shocking the audience with a sudden scare. 


\section{Section 4: Biological universals in specific fears}

Some specific events and environments are so consistently threatening, that fear towards them does not seemingly require any learning and is considered innate. For example, rat pups are afraid of the smell of cat even when they have never been exposed to cats, suggesting innate basis for such protective response ${ }^{75}$. Similarly, human infants almost invariably express stranger anxiety - fear towards unknown individuals - between 6 and 12 months of age despite never having any negative experiences with them ${ }^{76}$. Research in human adults also confirms that we may be prewired to be afraid of specific threats. This is saliently evidenced by the prevalence of phobias - severely disturbing and irrational fears towards specific objects. Phobias can be associated with a wide range of targets ranging from animals to specific locales, but studies have consistently shown that phobias are most commonly associated with situations and events that are evolutionarily significant and actually dangerous, such as snakes, spiders, heights, and other humans (see Figure $5 \mathrm{~A}$ ) ${ }^{77}$. This suggests that brain has an innate tendency for prioritizing protection from certain elements that the evolution has flagged as most threatening ${ }^{78}$ and this sensitivity makes phobias towards survival-salient events more common.

Such innate preparedness toward specific fears is also mirrored in population-based studies on healthy adults (Figure 5B). Most common fears pertain to the social domain and losing of close ones. Because humans are strongly social species and dependent on the closely-knit social networks, this kinds of losses are obviously detrimental to our well-being ${ }^{79,80}$. After the social losses, the next most frightening events comprise direct physical threats such as ending up in constricted spaces with lack of escape route and becoming injured or under extreme stress, such as being tortured or living in wartime. The only specific animal reaching the top ten list was snake. Many common horror / thriller movie tropes ended up also reasonably high on the list, such as accidents (24 / 130), murderers (34 / 130), terrorist attacks (37 / 130). However, in real life supernatural phenomena were not common causes of fear (92 / 130) even though they are common theme in horror movies (see Figure 6).

Recommendations: Triggering fear and terror based on universally feared objects and situations is a "safe" strategy that work in large audiences. However, this lacks novelty and originally, thus lowering the fear factor. Thus, this method should be used sparingly and in tandem with other techniques for scaring the audience. 

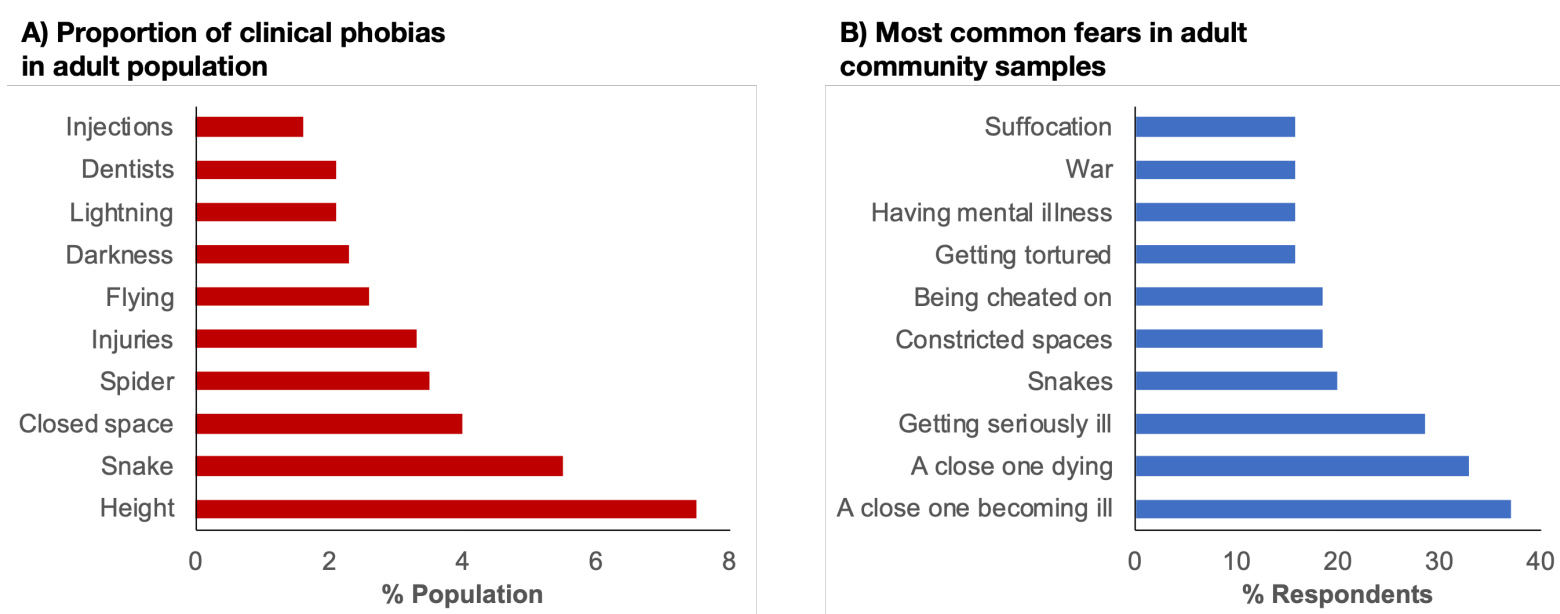

Figure 5. A) Most common targets of clinical phobias and B) most common non-clinical fears. The clinical data are reproduced from ${ }^{77}$ and those pertaining the healthy population from a previously unpublished dataset of 1,000 Finnish respondents.

\section{Most fearful content in horror movies}

The data on the biological universals in fear are also paralleled with ratings of horror movies (Figure 6). In a survey on the scariness of different horror movie genres, movies based on real events and psychological horror were topping the list ${ }^{23}$, as could be expected based on the prevalence of phobias and fears in healthy populations. Movies based on unrealistic themes such as monsters or sci-fi environments were rated as significantly less scary. Thus, successful horror stories are not just realistic in terms of presentation, they also have to be believable content-wise.

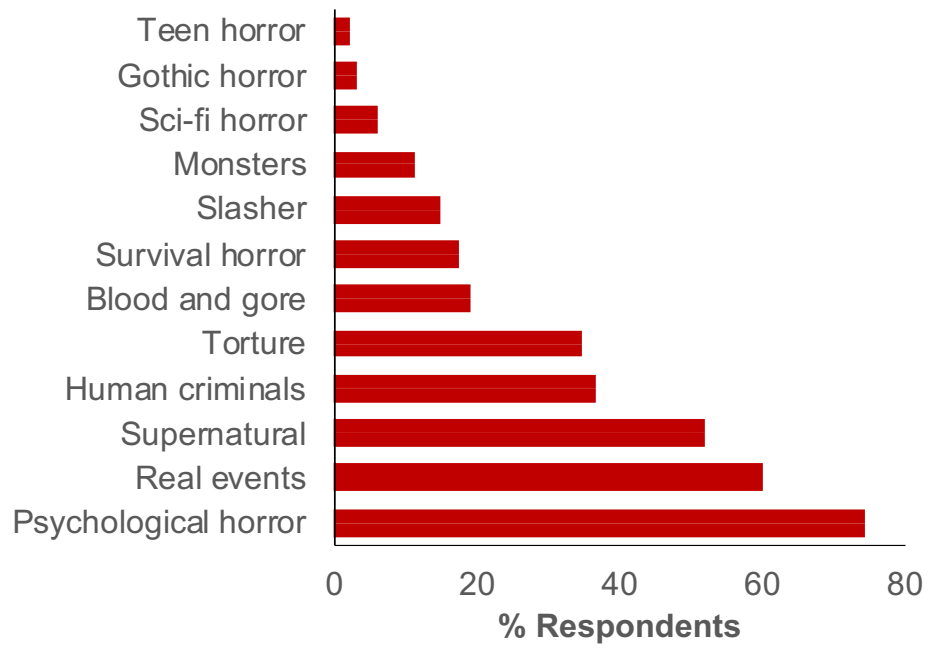

Figure 6. Scariest types of horror movies. The data show the proportion of respondents considering each horror movie genre as scary. Modified from ${ }^{23}$.

Some studies have also addressed the general contents (Table 1) of the horror movies that are considered as scariest ${ }^{23}$. In line with the data on prevalence of clinical phobias and prevalence of fears in healthy populations, these data suggest that movies that are based on plausible settings and events (such as psychological horror and movies 
based on real events; Figure 6) are in general considered as scariest, while more clearly implausible sci-fi horror movies or those based on monsters were evaluated as less scary. The only exception to this is movies with supernatural content - possibly because these movies close enough to real life so that they pass the brain's reality filter as believable.

\section{The impact of low-level visual features}

Finally, some studies have also tested whether specific low-level visual features such as spatial frequency composition and colour (in addition to the actual content and events) are associated with specific emotions. Most consistent effects are found for saturation and brightness: Scenes with both dark and desaturated colours are systematically experienced as unpleasant ${ }^{81}$; this likely reflects the general disliking and fear for darkness ${ }^{63,64}$. The evidence for spectral composition effects is limited with no clear effects on emotional response ${ }^{82}$. The evidence for colour-emotion pairing is mixed. Some cross-cultural studies have found that fear is universally associated with the black colour. This could arise from findings suggest that cross-modal associations could originate from both universal human experiences or cultural factors such as language, mythology, and literature ${ }^{83}$. However, similar colour-emotion parings are not observed in all studies ${ }^{84}$.

\section{Learned fears}

Humans have a striking array of fears, ranging from strangers to heights, illnesses, cemeteries and different animals. This brevity is partially explained by learning: repeated exposure to fear and anxiety can easily lead to association between the fear and the originally non-threatening event or context in which the fear was associated, thus leading to learning of novel fears ${ }^{3}$. Fear system is powerful because it provides flexible and effective means for learning new threats ${ }^{85}$. Such sensitivity in fear learning is important, as it allows humans and other animals to adapt to novel threats in their environment. Learning can be also exploited to manipulate fears in movies. Fear can be built upon the cultural conventions and shared knowledge on what constitutes dangerous. This may range from general long-standing beliefs (e.g. afterlife, spirits), generalized beliefs (fear of mental wards or prisons) to regional mythology and urban myths (folk stories of haunted houses, myth of the Slender Man). Using such beliefbased threat signals is however difficult for regional audiences if the beliefs are not widely enough spread. However, nowadays the beliefs can be spread quickly (both deliberately and spontaneously) through conventional and social media.

Cemetery is a classic staple of western horror movies and ghost stories. Although in purely empirical terms they are perfectly safe places, the clichéd scene of a thunderstorm breaking down in a dark, ruining cemetery leads the audience to expect a forthcoming supernatural thriller or horror movie. However, appreciating the terror of the scene requires that we know that the place is a cemetery, and that we have 
learned to believe that the dead people might continue to exist in some supernatural form. Without such knowledge and experience, the cemetery might feel just like another unusual location. Finally, movies themselves are an effective means for generating expectations of fear and horror. Within a single movie, repeated pairings between shocking events and jump-scares and specific environments, objects and characters may generate movie-specific fears. Some of these may be so effective that they become recurring tropes in horror movies, such masked killers (Hannibal Lecter, Ghostface, Jason Vorhees) or creepy dolls (Annabelle). Sometimes these are even overused to such extent that they become humorous: The classical horror trope of Indian burial ground has been extrapolated and repeated so many times that it has become a source of parody and is no longer experienced as particularly threatening.

Recommendations: Potentiated fear learning can be used for amplifying fear in movies in two ways. First, by choosing evolutionarily salient sources of threat with high potency for triggering fear) and second, by pairing that repeatedly in fearful context (see above). This way novel targets for fear can be generated during the movie viewing experience. Due to the automatic nature of fear learning ${ }^{86}$ the audience i) does not necessarily even notice learning new fears and ii) can also be subsequently shocked by scenes that were originally neutral, giving rise to unique cinematic experiences.

\section{Soundscape of dread}

Sound is an effective indicator of dangers, as we can hear a nearly 360-degree soundscape around us (in contrast with about 200 degrees field of view). Although humans primarily use vision for guiding their exploration of the environment, acoustic information is nevertheless important because it helps us to localize and identify targets out of eyesight, such as those behind us or those obstructed by scenery or objects. Sound design is also central to cinema and particularly horror movies practically no horror movie feels particularly scary if watched with sound turned down! Research suggests that sounds associated with direct threat such as fearful or aggressive human vocalizations are recognized universally, thus suggesting biological basis of their communication ${ }^{87}$. Accordingly, the brain rapidly and automatically differentiates between safe and threatening sounds, and for example fearful vocalizations (screams) result in a differential brain signature already $150 \mathrm{~ms}$ after the sound onset, suggesting highly automated processing of emotional sounds ${ }^{88}$. Sound is thus a convenient way of inducing thrills, as it is constantly processed in the background and in parallel and independently with the visuals.

As with fears in general, timing is critical for the sound effects. The fear inducing effects of sounds are significantly stronger when the sounds are louder versus softer, and when they match with the visual events, that is, when they occur due to clearly distinguishable visual event ${ }^{89}$. Sometimes it has also been argued that low-frequency sounds below the typical audible range in humans (i.e. beneath $20 \mathrm{~Hz}$ ) could trigger 
unpleasant sensations, nausea, and anxiety. The evidence for this is however mixed. Although high levels ( 150 dB) of naturally occurring low frequency sounds may have physiological effects in humans that subsequently lead to discomfort, they are difficult to use in theatres and concert venues due to the need of special sound systems for reproducing low frequency sounds 90 . Humans produce harsh, unpredictable, nonlinear sounds (screams) when they are afraid or alarmed. This kind of distress or alert signals sound harsh possibly because the vocal cords and syrinxes are overblown when used in stressful, dangerous situations. Studies have consistently found that this kind of rough and dissonant sounds are perceived as alarming, particularly when generated with modulation rates of $30-160 \mathrm{~Hz}$. The brains' fear circuit is also attuned to this frequency ${ }^{91}$. The alerting fearful screams occupy a specific location in the acoustic space, and humans automatically assess this type of sounds alerting and fearful. This kind of sounds are also very difficult to ignore, and they push easily to our awareness, making them powerful startling signals ${ }^{92}$. These principles can be applied to practically any sound effect. Additionally, synthetic sounds effects can be used for mood manipulation. Although not scary per se, unusual, looming sounds can provoke anxiety and vigilance because listeners simply cannot identify them.

\section{Composing fearful music}

Music can be used for communicating a multitude of emotions ${ }^{93,94}$ although musical conventions vary across cultures ${ }^{95}$. Brain imaging studies have found that fearful music engages the brain's fear circuit similarly as "natural" affective sounds such as vocalizations ${ }^{96}$, thus providing an unobtrusive means for manipulating emotions outside audience's awareness. Different nonlinearities can be induced into music and soundtracks with technological manipulations and adding noise and abrupt frequency modulations makes the music sound more arousing. Indeed, scary scenes from horror films contain this kind of noisy elements for amplifying the experience of horror, while dramatic films suppress this kind of noise ${ }^{97}$. Music is however less consistent elicitor of emotions across individuals than sounds directly mimicking threats or threat signals. Research has shown that a great portion of the emotion-evoking power of music is learned, and musical emotions stem often from autobiographical events associated with the music as well as nostalgia ${ }^{98-100}$. This makes tailoring of one-size-fits all music more difficult, warranting careful pre-testing with test audiences.

Recommendations: Sound design is important in horror movies because it allows indirect manipulation of suspense and anxiety. Although viewers are focused on the visuals of the movie, acoustic information is constantly processed and can be used for guiding attention and emotion without audience's deliberate attention. Sounds can also easily generate powerful startling effects, and specific sounds and sound types can automatically turn on the brain's survival circuits. Finally, sound effects can be used for increasing alertness and feelings of unease, as it is possible to generate synthetic sounds that the listeners cannot readily identify, increasing their scariness further. 


\section{Section 5: Conclusions - why do we enjoy horror movies? What makes a specific horror movie enjoyable?}

Horror movies seem paradoxical - why would anyone be willing to pay to be able to be afraid and constantly shocked? One study has directly investigated which features and contents of horror movies might contribute to the enjoyability of the movies. This study identified four candidate factors: suffering of the characters, perceived danger, excitement and happy versus unhappy ending ${ }^{101}$. Of these factors, particularly suffering and danger were associated with enjoyment of horror. Although graphic violence is a recurring theme in horror movies, it is nor critical for making horror movies enjoyable. Another study compared audience responses to a graphically violent film and its edited version where the violent scenes were toned down or completely removed. The nonviolent version was significantly more enjoyable than the two violent versions, confirming that violence per se does not increase enjoyment of movies ${ }^{102}$. However, when administered skilfully it can increase the startle responses during jump scares, or temporarily ramp up the fearfulness of the scenes.

Table 1. Candidate factors driving enjoyment in horror in movies. Modified from ${ }^{101}$.

\begin{tabular}{|c|c|c|c|}
\hline Suffering & Danger & Excitement & Happy ending \\
\hline Watching a character suffer & $\begin{array}{l}\text { Knowing a killer is about } \\
\text { to attack an } \\
\text { unsuspecting character }\end{array}$ & Thrilling sequences & $\begin{array}{l}\text { A happy } \\
\text { ending with } \\
\text { the threat } \\
\text { eliminated }\end{array}$ \\
\hline $\begin{array}{l}\text { Close-ups of the victim in } \\
\text { agony }\end{array}$ & $\begin{array}{l}\text { Knowing a character is } \\
\text { about to walk into a trap }\end{array}$ & Suspense & $\begin{array}{l}\text { When a } \\
\text { threatened } \\
\text { character } \\
\text { escapes harm }\end{array}$ \\
\hline Gruesome death scenes & $\begin{array}{l}\text { Anticipating something } \\
\text { scary }\end{array}$ & Action sequences & \\
\hline Blood and gore & $\begin{array}{l}\text { When a character is } \\
\text { unaware of impending } \\
\text { danger }\end{array}$ & Excitement & \\
\hline $\begin{array}{l}\text { Listening to someone in } \\
\text { pain }\end{array}$ & $\begin{array}{l}\text { Music that signals the } \\
\text { approach of danger }\end{array}$ & & \\
\hline Mutilation of body parts & $\begin{array}{l}\text { Sounds suggesting } \\
\text { danger }\end{array}$ & & \\
\hline \multicolumn{4}{|l|}{ Graphic, bloody violence } \\
\hline Characters being tortured & & & \\
\hline
\end{tabular}

\section{Why are horror movies popular in the first place?}

There are multiple reasons why horror movies are so popular. First, despite being wary of the unknown, humans have a strong curiosity and fascination with the unusual ${ }^{103}$, and negative emotions experienced while viewing horror movies consistently predict how enjoyable the viewers experience the movie to be ${ }^{24}$. We seek out coverage of 
violence in the news and on the internet and are similarly drawn towards thrillers and horror movies. This is driven by sensation seeking motivation, as the scares and morbidities give rise to arousing sensations, which might be experienced as pleasant when experienced in otherwise safe environment ${ }^{104}$. Indeed, fear and excitement have in many parts overlapping neurobiological basis, the most salient parallels being the hypothalamus-driven control of the physiological stress response, which may lead to "mixing" of these two emotions, and fear may be experienced as exciting. Alternatively, we may be curious about the unusual and negative events because they allow us to learn new things about the world ${ }^{105}$. Finally, horror movies may act as a "mental gym" or training ground for the mind. During the safe environment of the movie theatre, we may be psychologically and somatically exposed to events that would be life-threatening if encountered for real. This way the mind can learn to prepare scripts for action during real emergencies, and also learn to cope with the difficult emotions (anxiety, fear, sadness) so that we are better prepared for dealing with them whenever they come to us in real life. This could also explain why people have so strong preference for horror movies that are both plausible and based on realistic settings (Figure 6).

In sum, a healthy dose of scares in a horror movie (or tears in a heart-breaking drama) can be psychologically beneficial. Learning how different emotions feel and being exposed to them in a safe, controllable environment builds up psychological resilience helps in dealing with difficult emotions in real life.

Recommendations: Because enjoyment of horror stems from curiosity, the audience should be made interested in the movie. It is simply not enough to shock the viewers repeatedly. Instead, novelty and surprise are critical elements for an enjoyable horror movie experience. Constantly providing new details and slowly unravelling the plotline are effective devices for keeping up the interest and increasing the excitement of the movie. 


\section{References}

1 Adolphs, R. The Biology of Fear. Curr. Biol. 23, R79-R93, doi:10.1016/j.cub.2012.11.055 (2013).

2 Mobbs, D., Hagan, C. C., Dalgleish, T., Silston, B. \& Prevost, C. The Ecology of Human Fear: Survival Optimization and the Nervous System. Front.

Neurosci. 9, 22, doi:10.3389/fnins.2015.00055 (2015).

3 LeDoux, J. E. Emotion Circuits in the Brain. Annual Review of Neuroscience 23, 155-184, doi:10.1146/annurev.neuro.23.1.155 (2000).

4 Baumeister, R. F., Bratslavsky, E., Finkenauer, C. \& Vohs, K. D. Bad Is Stronger Than Good. Review of General Psychology 5, 323-370, doi:10.1037/1089-2680.5.4.323 (2001).

5 Vuilleumier, P. How Brains Beware: Neural Mechanisms of Emotional Attention. Trends Cogn. Sci. 9, 585-594, doi:10.1016/j.tics.2005.10.011 (2005).

6 Nummenmaa, L., Glerean, E., Hari, R. \& Hietanen, J. K. Bodily Maps of Emotions. Proc. Natl. Acad. Sci. U. S. A. 111, 646-651, doi:10.1073/pnas.1321664111 (2014).

7 Nummenmaa, L., Hari, R., Hietanen, J. K. \& Glerean, E. Maps of Subjective Feelings. Proc. Natl. Acad. Sci. U. S. A. 115, 9198-9203 (2018).

8 Fanselow, M. S. \& Lester, L. S. in Evolution and Learning (eds R.C. Bolles \& M.D. Beecher) 185-211 (Erlbaum, 1988).

9 McNaughton, N. \& Corr, P. J. A Two-Dimensional Neuropsychology of Defense: Fear/Anxiety and Defensive Distance Neurosci. Biobehav. Rev. 28, 285-305 (2004).

10 Mobbs, D. et al. Neural Activity Associated with Monitoring the Oscillating Threat Value of a Tarantula. Proc. Natl. Acad. Sci. U. S. A. 107, 20582-20586, doi:10.1073/pnas.1009076107 (2010).

11 Adolphs, R., Tranel, D., Damasio, H. \& Damasio, A. Impaired Recognition of Emotion in Facial Expressions Following Bilateral Damage to the Human Amygdala. Nature 372, 669-672, doi:10.1038/372669a0 (1994).

12 Calder, A. J., Lawrence, A. D. \& Young, A. W. Neuropsychology of Fear and Loathing. Nature Reviews Neuroscience 2, 352, doi:10.1038/35072584 (2001).

13 Feinstein, J. S., Adolphs, R., Damasio, A. \& Tranell, D. The Human Amygdala and the Induction and Experience of Fear. Curr. Biol. 21, 34-38, doi:10.1016/j.cub.2010.11.042 (2011).

14 Saarimäki, H. et al. Discrete Neural Signatures of Basic Emotions. Cereb. Cortex 6, 2563-2573, doi:10.1093/cercor/bhv086 (2016).

15 Ochsner, K. N., Bunge, S. A., Gross, J. J. \& Gabrieli, J. D. E. Rethinking Feelings: An Fmri Study of the Cognitive Regulation of Emotion. Journal of Cognitive Neuroscience 14, 1215-1229 (2002). 
16 Mobbs, D. et al. When Fear Is Near: Threat Imminence Elicits PrefrontalPeriaqueductal Gray Shifts in Humans. Science 317, 1079-1083, doi:10.1126/science.1144298 (2007).

17 Volynets, S., Glerean, E., Hietanen, J. K., Hari, R. \& Nummenmaa, L. Bodily Maps of Emotions Are Culturally Universal. Emotion (Washington, D.C.), doi:10.1037/emo0000624 (2019).

18 Bishop, S., Duncan, J. \& Lawrence, A. D. Prefrontal Cortical Function and Anxiety: Controlling Attention to Threat-Related Stimuli. Nature neuroscience 7, 184-188, doi:10.1038/nn1173 (2004).

19 Yarkoni, T., Poldrack, R. A., Nichols, T. E., Van Essen, D. C. \& Wager, T. D. Neurosynth: A New Platform for Large-Scale Automated Synthesis of Human Functional Neuroimaging Data. Frontiers in Neuroinformatics, doi:10.3389/conf.fninf.2011.08.00058 (2011).

20 Zheng, J. et al. Amygdala-Hippocampal Dynamics During Salient Information Processing. Nature Communications 8, 14413, doi:10.1038/ncomms14413 (2017).

21 Kinreich, S., Intrator, N. \& Hendler, T. Functional Cliques in the Amygdala and Related Brain Networks Driven by Fear Assessment Acquired During Movie Viewing. Brain connectivity 1, 484-495, doi:10.1089/brain.2011.0061 (2011).

22 Nummenmaa, L. et al. Emotions Promote Social Interaction by Synchronizing Brain Activity across Individuals. Proc. Natl. Acad. Sci. U. S. A. 109, 95999604, doi:10.1073/pnas.1206095109 (2012).

23 Hudson, M. et al. Dissociable Neural Systems for Unconditioned Acute and Sustained Fear. Neuroimage 216, 116522, doi:https://doi.org/10.1016/j.neuroimage.2020.116522 (2020).

24 Hoffner, C. A. \& Levine, K. J. Enjoyment of Mediated Fright and Violence: A Meta-Analysis. Media Psychology 7, 207-237, doi:10.1207/S1532785XMEP0702_5 (2005).

25 Urry, H. L. \& Gross, J. J. Emotion Regulation in Older Age. Current Directions in Psychological Science 19, 352-357, doi:10.1177/0963721410388395 (2010).

26 Adolphs, R., Nummenmaa, L., Todorov, A. \& Haxby, J. V. Data-Driven Approaches in the Investigation of Social Perception. Phil Trans B 371 (2016).

27 Raij, T. T. et al. Reality of Auditory Verbal Hallucinations. Brain 132, 29943001, doi:10.1093/brain/awp186 (2009).

28 Lin, J.-H. T. Fear in Virtual Reality (Vr): Fear Elements, Coping Reactions, Immediate and Next-Day Fright Responses toward a Survival Horror Zombie Virtual Reality Game. Comput. Hum. Behav. 72, 350-361, doi:https://doi.org/10.1016/j.chb.2017.02.057 (2017). 
29 Hasson, U., Malach, R. \& Heeger, D. J. Reliability of Cortical Activity During Natural Stimulation. Trends Cogn. Sci. 14, 40-48, doi:10.1016/j.tics.2009.10.011 (2010).

30 Dimberg, U. \& Thunberg, M. Rapid Facial Reactions to Emotional Facial Expressions. Scand. J. Psychol. 39, 39-45 (1998).

31 Hietanen, J. K., Surakka, V. \& Linnankoski, I. Facial Electromyographic Responses to Vocal Affect Expressions. Psychophysiology 35, 530-536, doi:10.1017/s0048577298970445 (1998).

32 Wild, B., Erb, M. \& Bartels, M. Are Emotions Contagious? Evoked Emotions While Viewing Emotionally Expressive Faces: Quality, Quantity, Time Course and Gender Differences. Psychiatry Res. 102, 109-124 (2001).

33 Jackson, P. L., Meltzoff, A. N. \& Decety, J. How Do We Perceive the Pain of Others? A Window into the Neural Processes Involved in Empathy. Neurolmage 24, 771-779 (2005).

34 Saarela, M. V. et al. The Compassionate Brain: Humans Detect Intensity of Pain from Another's Face. Cereb. Cortex 17, 230-237, doi:10.1093/cercor/bhj141 (2007).

35 Singer, T. et al. Empathy for Pain Involves the Affective but Not Sensory Components of Pain. Science 303, 1157-1162 (2004).

36 Wicker, B. et al. Both of Us Disgusted in My Insula: The Common Neural Basis of Seeing and Feeling Disgust. Neuron 40, 655-664 (2003).

37 Jabbi, M., Swart, M. \& Keysers, C. Empathy for Positive and Negative Emotions in the Gustatory Cortex. Neurolmage 34, 1744-1753 (2007).

38 Hatfield, E., Cacioppo, J. \& Rapson, R. L. Emotional Contagion. (Cambridge University Press, 1994).

39 Niedenthal, P. M. Embodying Emotion. Science 316, 1002-1005, doi:10.1126/science.1136930 (2007).

40 Keysers, C., Kaas, J. H. \& Gazzola, V. Somatosensation in Social Perception. Nature Reviews Neuroscience 11, 417-428, doi:10.1038/nrn2833 (2010).

41 Platek, S. M., Critton, S. R., Myers, T. E. \& Gallup, G. G. Contagious Yawning: The Role of Self-Awareness and Mental State Attribution. Cognit. Brain Res. 17, 223-227, doi:10.1016/s0926-6410(03)00109-5 (2003).

42 Scott, S. K., Lavan, N., Chen, S. \& McGettigan, C. The Social Life of Laughter. Trends Cogn. Sci. 18, 618-620, doi:10.1016/j.tics.2014.09.002 (2015).

43 Karjalainen, T. et al. Dissociable Roles of Cerebral Mu-Opioid and Type 2 Dopamine Receptors in Vicarious Pain: A Combined Pet-Fmri Study. Cerebral cortex (New York, N.Y. : 1991), 1-10, doi:10.1093/cercor/bhx129 (2017).

44 Decety, J., Norman, G. J., Berntson, G. G. \& Cacioppo, J. T. A Neurobehavioral Evolutionary Perspective on the Mechanisms Underlying Empathy. Prog. Neurobiol. 98, 38-48, doi:10.1016/j.pneurobio.2012.05.001 (2012). 
45 Preston, S. D. \& de Waal, F. B. M. Empathy: Its Ultimate and Proximate Bases. Behav. Brain Sci. 25, 1-+ (2002).

46 Singer, T. et al. Empathy for Pain Involves the Affective but Not Sensory Components of Pain. Science 303, 1157-1162, doi:10.1126/science.1093535 (2004).

47 Avenanti, A., Sirigu, A. \& Aglioti, S. M. Racial Bias Reduces Empathic Sensorimotor Resonance with Other-Race Pain. Curr. Biol. 20, 1018-1022, doi:10.1016/j.cub.2010.03.071 (2010).

48 Singer, T. et al. Empathic Neural Responses Are Modulated by the Perceived Fairness of Others. Nature 439, 466-469, doi:10.1038/nature04271 (2006).

49 Rosen, J. B. \& Schulkin, J. From Normal Fear to Pathological Anxiety. Psychol. Rev. 105, 325-350, doi:10.1037/0033-295x.105.2.325 (1998).

50 Grupe, D. W. \& Nitschke, J. B. Uncertainty and Anticipation in Anxiety: An Integrated Neurobiological and Psychological Perspective. Nature Reviews Neuroscience 14, 488-501, doi:10.1038/nrn3524 (2013).

51 Carleton, R. N. Fear of the Unknown: One Fear to Rule Them All? Journal of Anxiety Disorders 41, 5-21, doi:https://doi.org/10.1016/j.janxdis.2016.03.011 (2016).

52 Klucken, T. et al. Contingency Learning in Human Fear Conditioning Involves the Ventral Striatum. Human Brain Mapping 30, 3636-3644, doi:10.1002/hbm.20791 (2009).

53 Holt-Lunstad, J., Smith, T. B. \& Layton, J. B. Social Relationships and Mortality Risk: A Meta-Analytic Review. PLoS Med 7, e1000316, doi:10.1371/journal.pmed.1000316 (2010).

54 Holt-Lunstad, J., Smith, T. B., Baker, M., Harris, T. \& Stephenson, D. Loneliness and Social Isolation as Risk Factors for Mortality: A Meta-Analytic Review. Perspect. Psychol. Sci. 10, 227-237, doi:10.1177/1745691614568352 (2015).

55 Tedeschi, E., Weber, J., Prevost, C., Mischel, W. \& Mobbs, D. Inferences of Others' Competence Reduces Anticipation of Pain When under Threat. J. Cogn. Neurosci. 27, 2071-2078, doi:10.1162/jocn_a_00843 (2015).

56 Sherif, M., Harvey, O. J., White, B. J., Hood, W. \& Sherif, C. W. Intergroup Conflict and Cooperation: The Robbers Cave Experiment. (University of Oklahoma Book Exchange, 1961).

57 Brewer, M. B. In-Group Bias in the Minimal Intergroup Situation - CognitiveMotivational Analysis. Psychol. Bull. 86, 307-324, doi:10.1037/00332909.86.2.307 (1979).

58 Kinzler, K. D., Corriveau, K. H. \& Harris, P., L. Children's Selective Trust in Native-Accented Speakers. Developmental Science 14, 106-111, doi:10.1111/j.1467-7687.2010.00965.x (2010).

59 Baumeister, R. F. Evil: Inside Human Violence and Cruelty. (Henry Holt and Company, LCC, 1997). 
60 Mori, M. The Uncanny Valley (Bukimi No Tani). Energy 7, 33-35 (1970).

61 Steckenfinger, S. A. \& Ghazanfar, A. A. Monkey Visual Behavior Falls into the Uncanny Valley. Proceedings of the National Academy of Sciences 106, 18362 (2009).

62 Mathur, M. B. \& Reichling, D. B. Navigating a Social World with Robot Partners: A Quantitative Cartography of the Uncanny Valley. Cognition 146, 22-32, doi:https://doi.org/10.1016/j.cognition.2015.09.008 (2016).

63 Ponchillia, P. E., Laduke, R. O. \& Lagrow, S. J. The Measurement of Stress in Nonvisual Travel. Education of the Visually Handicapped 16, 21-29 (1984).

64 Grillon, C., Pellowski, M., Merikangas, K. R. \& Davis, M. Darkness Facilitates the Acoustic Startle Reflex in Humans. Biological psychiatry 42, 453-460, doi:10.1016/s0006-3223(96)00466-0 (1997).

65 Riekki, T., Lindeman, M., Aleneff, M., Halme, A. \& Nuortimo, A. Paranormal and Religious Believers Are More Prone to Illusory Face Perception Than Skeptics and Non-Believers. Appl. Cogn. Psychol. 27, 150-155, doi:10.1002/acp.2874 (2013).

66 Caputo, G. B. Strange-Face-in-the-Mirror Illusion. Perception 39, 1007-1008, doi:10.1068/p6466 (2010).

67 Lang, P. J. The Emotion Probe - Studies of Motivation and Attention. Am. Psychol. 50, 372-385, doi:10.1037//0003-066x.50.5.372 (1995).

68 Vrana, S. R., Spence, E. L. \& Lang, P. J. The Startle Probe Response - a New Measure of Emotion. J. Abnorm. Psychol. 97, 487-491, doi:10.1037/0021843x.97.4.487 (1988).

69 Cantor, J., Ziemke, D. \& Sparks, G. G. Effect of Forewarning on Emotional Responses to a Horror Film. Journal of Broadcasting 28, 21-31, doi:10.1080/08838158409386512 (1984).

70 Grill-Spector, K., Henson, R. \& Martin, A. Repetition and the Brain: Neural Models of Stimulus-Specific Effects. Trends Cogn. Sci. 10, 14-23, doi:10.1016/j.tics.2005.11.006 (2006).

71 Manninen, S. et al. Social Laughter Triggers Endogenous Opioid Release in Humans. The Journal of Neuroscience 37, 6125-6131 (2017).

72 Harris, P. L., Brown, E., Marriott, C., Whittall, S. \& Harmer, S. Monsters, Ghosts and Witches - Testing the Limits of the Fantasy Reality Distinction in Young-Children. Br. J. Dev. Psychol. 9, 105-123, doi:10.1111/j.2044835X.1991.tb00865.x (1991).

73 Keinan, G. The Effects of Stress and Desire for Control on Superstitious Behavior. Pers. Soc. Psychol. Bull. 28, 102-108, doi:10.1177/0146167202281009 (2002).

74 Dudley, R. T. The Effect of Superstitious Belief on Performance Following an Unsolvable Problem. Pers. Individ. Differ. 26, 1057-1064, doi:10.1016/s01918869(98)00209-8 (1999). 
75 Panksepp, J. Affective Neuroscience: The Foundations of Human and Animal Emotions. (Oxford University Press, 1998).

76 Brooker, R. J. et al. The Development of Stranger Fear in Infancy and Toddlerhood: Normative Development, Individual Differences, Antecedents, and Outcomes. Developmental Science 16, 864-878, doi:10.1111/desc.12058 (2013).

77 Fredrikson, M., Annas, P., Fischer, H. \& Wik, G. Gender and Age Differences in the Prevalence of Specific Fears and Phobias. Behav. Res. Ther. 34, 33-39, doi:10.1016/0005-7967(95)00048-3 (1996).

78 Ohman, A. \& Mineka, S. Fears, Phobias, and Preparedness: Towards an Evolved Module of Fear and Fear Learning. Psychological Review 108, 483522 (2001).

79 Dunbar, R. I. M. Mind the Gap: Or Why Humans Aren't Just Great Apes. Proceedings of the British Academy 154, 403-423 (2008).

80 Dunbar, R. I. M. \& Shultz, S. Bondedness and Sociality. Behaviour, 775-803 (2010).

81 Valdez, P. \& Mehrabian, A. Effects of Color on Emotions. J. Exp. Psychol.Gen. 123, 394-409, doi:10.1037/0096-3445.123.4.394 (1994).

82 Delplanque, S., N'diaye, K., Scherer, K. \& Grandjean, D. Spatial Frequencies or Emotional Effects?: A Systematic Measure of Spatial Frequencies for laps Pictures by a Discrete Wavelet Analysis. Journal of Neuroscience Methods 165, 144-150, doi:https://doi.org/10.1016/j.jneumeth.2007.05.030 (2007).

83 Hupka, R. B., Zaleski, Z., Otto, J., Reidl, L. \& Tarabrina, N. V. The Colors of Anger, Envy, Fear, and Jealousy: A Cross-Cultural Study. J. Cross-Cult. Psychol. 28, 156-171, doi:10.1177/0022022197282002 (1997).

84 Fugate, J. M. B. \& Franco, C. L. What Color Is Your Anger? Assessing ColorEmotion Pairings in English Speakers. Frontiers in Psychology 10, 206 (2019).

85 Ohman, A., Eriksson, A. \& Olofsson, C. One-Trial Learning and Superior Resistance to Extinction of Autonomic Responses Conditioned to Potentially Phobic Stimuli. Journal of Comparative and Physiological Psychology 88, 619-627 (1975).

86 LeDoux, J. E. in Evolution of the Primate Brain: From Neuron to Behavior Vol. 195 Progress in Brain Research (eds M. A. Hofman \& D. Falk) 431-442 (2012).

87 Sauter, D. A., Eisner, F., Ekman, P. \& Scott, S. K. Cross-Cultural Recognition of Basic Emotions through Nonverbal Emotional Vocalizations. Proc. Natl. Acad. Sci. U. S. A. 107, 2408-2412, doi:10.1073/pnas.0908239106 (2010).

88 Sauter, D. A. \& Eimer, M. Rapid Detection of Emotion from Human Vocalizations. J. Cogn. Neurosci. 22, 474-481, doi:10.1162/jocn.2009.21215 (2010).

89 Toprac, P. \& Abdel-Megiud, A. in Game Sound Technology and Player Interaction: Concepts and Developments (ed M. Grimshaw) 176-191 (IGI Global, 2010). 
90 Leventhall, G., Pelmear, P. \& Benton, S. (ed Food and Rural Affairs Department for Environment) (Defra Publications, London, 2003).

91 Arnal, Luc H., Flinker, A., Kleinschmidt, A., Giraud, A.-L. \& Poeppel, D. Human Screams Occupy a Privileged Niche in the Communication Soundscape. Curr. Biol. 25, 2051-2056, doi:https://doi.org/10.1016/j.cub.2015.06.043 (2015).

92 Fitch, W. T., Neubauer, J. \& Herzel, H. Calls out of Chaos: The Adaptive Significance of Nonlinear Phenomena in Mammalian Vocal Production. Anim. Behav. 63, 407-418, doi:https://doi.org/10.1006/anbe.2001.1912 (2002).

93 Zentner, M., Grandjean, D. \& Scherer, K. R. Emotions Evoked by the Sound of Music: Characterization, Classification, and Measurement. Emotion 8, 494521, doi:10.1037/1528-3542.8.4.494 (2008).

94 Eerola, T. \& Vuoskoski, J. K. A Review of Music and Emotion Studies: Approaches, Emotion Models, and Stimuli. Music Perception: An Interdisciplinary Journal 30, 307, doi:10.1525/mp.2012.30.3.307 (2013).

95 Cowen, A. S., Fang, X., Sauter, D. \& Keltner, D. What Music Makes Us Feel: At Least 13 Dimensions Organize Subjective Experiences Associated with Music across Different Cultures. Proceedings of the National Academy of Sciences 117, 1924, doi:10.1073/pnas. 1910704117 (2020).

96 Aubé, W., Angulo-Perkins, A., Peretz, I., Concha, L. \& Armony, J. L. Fear across the Senses: Brain Responses to Music, Vocalizations and Facial Expressions. Soc. Cogn. Affect. Neurosci. 10, 399-407, doi:10.1093/scan/nsu067 (2014).

97 Blumstein, D. T., Davitian, R. \& Kaye, P. D. Do Film Soundtracks Contain Nonlinear Analogues to Influence Emotion? Biology Letters 6, 751-754, doi:10.1098/rsbl.2010.0333 (2010).

98 Janata, P., Tomic, S. T. \& Rakowski, S. K. Characterisation of Music-Evoked Autobiographical Memories. Memory 15, 845-860, doi:10.1080/09658210701734593 (2007).

99 Janata, P. The Neural Architecture of Music-Evoked Autobiographical Memories. Cereb. Cortex 19, 2579-2594, doi:10.1093/cercor/bhp008 (2009).

100 Barrett, F. S. et al. Music-Evoked Nostalgia: Affect, Memory, and Personality. Emotion 10, 390-403, doi:10.1037/a0019006 (2010).

101 Hoffner, C. Affective Responses and Exposure to Frightening Films: The Role of Empathy and Different Types of Content. Communication Research Reports 26, 285-296, doi:10.1080/08824090903293700 (2009).

102 Weaver, A. J. \& Wilson, B. J. The Role of Graphic and Sanitized Violence in the Enjoyment of Television Dramas. Hum. Commun. Res. 35, 442-U437, doi:10.1111/j.1468-2958.2009.01358.x (2009).

103 Oosterwijk, S. Choosing the Negative: A Behavioral Demonstration of Morbid Curiosity. PLoS One 12, e0178399, doi:10.1371/journal.pone.0178399 (2017). 
104 Zuckerman, M. The Psychophysiology of Sensation Seeking. J. Pers. 58, 313345, doi:10.1111/j.1467-6494.1990.tb00918.x (1990).

105 Berlyne, D. E. Curiosity and Exploration. Science 153, 25-\&, doi:10.1126/science.153.3731.25 (1966). 